\title{
Neurological adverse events following regional anesthesia administration
}

\author{
This article was published in the following Dove Press journal: \\ Local and Regional Anesthesia \\ 23 October 2010 \\ Number of times this article has been viewed
}

\section{Christopher D Kent Laurent Bollag}

Department of Anesthesiology and Pain Medicine, University of Washington, Seattle, Washington, USA

\begin{abstract}
Regional anesthesia and analgesia have been associated with improved analgesia, decreased postoperative nausea and vomiting, and increased patient satisfaction for many types of surgical procedures. In obstetric anesthesia care, it has also been associated with improved maternal mortality and major morbidity. The majority of neurological adverse events following regional anesthesia administration result in temporary sensory symptoms; long-term or permanent disabling motor and sensory problems are very rare. Infection and hemorrhagic complications, particularly with neuraxial blocks, can cause neurological adverse events. More commonly, however, there are no associated secondary factors and some combination of needle trauma, intraneural injection, and/or local anesthetic toxicity may be associated, but their individual contributions to any event are difficult to define.
\end{abstract}

Keywords: postanesthetic neural deficits, transient neurologic symptoms, epidural abscess, neuraxial hematoma

\section{"First do no harm."}

"Life is short; the art is long. ... experience treacherous ..."

These statements attributed to Hippocrates have informed the thoughts and behavior of physicians for centuries and illustrate some of the challenges-facing anesthesiologists in the practice of regional anesthesia. Anesthesiologists recognize that there are risks associated with all procedures, but if they followed Hippocrates' first and most famous dictum too literally it would be impossible to take any therapeutic first steps, particularly for practitioners venturing away from the often more familiar world of general anesthesia. When considering regional anesthesia, the risk of doing harm is kept in perspective by recognizing the harm that is visited on patients in the form of poorly controlled pain and a poorly planned recovery after a surgical procedure. Then the question becomes what are the best techniques for the care of a patient in a specific setting; refining of our knowledge of associated risks is crucial to answering this question.

Hippocrates' other statement alludes to the limitations of relying solely on personal or local experience when it comes to building an understanding of a phenomenon such as neurological adverse events accompanying regional anesthesia, in part because they can be sufficiently uncommon that a perspective based even on a lifetime of personal experience will not provide a comprehensive view. The best understanding comes from balancing personal experience with a review of the best available external evidence, however incomplete that may be. The primary goal of this review is to inform the reader's personal continuous quality improvement journey which is the foundation for any institutional quality improvement processes. The focus is on recent literature to
Correspondence: Christopher D Kent Box 356540, Health Sciences BB-I469, 1959 NE Pacific Street, Seattle, WA 98। 95-6540, USA

Email kentc02@u.washington.edu submit your manuscript $\mid$ www.dovepress.com

Dovepress

DOI: $10.2147 /$ LRA.S8177 
provide up to date information on neurological adverse events and how to prevent them or at least minimize their impact on patients receiving regional anesthesia or analgesia.

\section{Overview}

The ideal studies to accurately capture the incidence and effects of neurologic adverse events would be large, prospective, multicenter studies with active surveillance, and an extended duration of follow-up. This sort of study requires extraordinary effort, coordination, and funding; consequently, the literature consists largely of smaller prospective studies from single centers or retrospective reviews with variable standards for outcome reporting. ${ }^{1}$ Studies of closed malpractice claims and anesthesia incident monitoring studies have the largest databases of complications, but the denominator for claim incidence is often insufficiently defined to make these good studies for precisely delineating the incidence of complications. They are more valuable for evaluating the type and severity of neurologic complications, particularly those with the most severe and long-lasting adverse outcomes.

Among the studies in the literature reporting on neurologic adverse events, there is wide variation in the estimates of incidence, with a number of potential contributing factors. In part, this may be due to study designs that result in different degrees of under-reporting, which has been noted to be a particular problem with outcome studies focusing on complications. ${ }^{2}$ Some of the variability in incidence may be due to differences in technique and practitioner experience from center to center. For example, there are studies reporting the outcomes of regional anesthetic procedures performed by a single provider or a small group of experienced providers; although these may provide information about what the optimal outcomes might be, these findings may not be generalizable to situations where providers of many levels of experience are involved.

The difficulty in attributing specific outcomes accurately to either anesthetic or surgical factors is also likely to play a role in the variation in incidence reporting. Regional anesthetics can involve a potentially perfect overlap between the anesthetized area and the site of the surgical procedure making the attribution of complications such as complex regional pain syndrome or nerve injury to either the anesthetic or the surgical procedure challenging if not, at times, impossible. Some studies use expert third-party assessment to attempt to determine the causes of neurologic adverse events, whereas other studies are not as clear or specific about the attribution process used. Although having the apparent advantage of objectivity, independent third-party assessors should not be considered to have de facto superiority, particularly if the assessment has not been supplemented by expert interpretation of nerve conduction and/or electromyographic (EMG) examinations and balanced with input from experienced anesthesiologists.

The timing and type of surveillance for complications employed in a study are important factors contributing to variability in incidence reporting. Although some complications, such as local anesthetic systemic toxicity (LAST) from intravascular injection of local anesthetics, present immediately and undeniably as seizures, the delayed appearance of postoperative neural deficits pose a greater challenge for detection, particularly if a relatively passive process such as voluntary self-reporting is used as opposed to direct patient interviews and examinations.

Perhaps, the most significant factor in the variability of reporting the incidence of neurologic adverse events is that sampling infrequent and rare events are prone to error, due to the possibility for either case clustering or its opposite, a sampling interval without events. For example, an often quoted risk estimate for the occurrence of spinal canal hematoma with epidural anesthesia is $1 / 150,000 .^{3,4}$ This means that if a group of dedicated investigators assembled a new case series or prospective study of 50,000 patients with epidural anesthetics and did not have any patients experience an epidural hematoma, using Hanley's rule for defining the 95\% confidence interval for an event that did not occur, ${ }^{5}$ the updated risk estimate $(0-1 / 16,667)$ would still include the historical estimate, adding to but not substantially refining our existing knowledge.

\section{Utility of regional anesthesia}

The most consistent benefits of regional anesthesia emerging from studies comparing it with general anesthesia have been improved analgesia, decreased postoperative nausea and vomiting, and increased patient satisfaction. ${ }^{6-10}$ For the practice of obstetric anesthesia, it is widely accepted that regional techniques have an advantage for maternal mortality. ${ }^{11,12}$ This mortality advantage has been asserted in other patient populations, but the results have not been as reproducible. ${ }^{13,14}$ Anecdotally, an opinion held by many anesthesiologists is that primary regional anesthesia is the safest form of anesthesia for patients with the most critical comorbidities. This notion will probably remain an assertion based primarily on experience and expert opinion; as it is unlikely to ever be validated or even tested within the context of an appropriately powered randomized clinical trial, due to the uncommon occurrence of mortality and major morbidity even in this high-risk group and the difficulties of randomizing these vulnerable patients to a specific anesthetic. ${ }^{15}$ 


\section{Types of neurological adverse events Postanesthetic neural deficits}

Neural deficits after regional anesthesia can occur in association with complications that cause compression of nerves such as infection or hematoma or more commonly without other obvious contributing complications. In spite of the attempts that have been made to assess and understand the cause of postanesthetic neural deficits (PAND) that occur without accompanying hematoma or infection, a great deal of uncertainty remains. Some of the candidate component factors leading to injury include the following:

- direct mechanical needle trauma to nerves

- mechanical trauma due to intraneural injection

- local anesthetic neurotoxicity

- ischemia due pressure/hydrostatic effects of perineural/ intraneural injection

- neurotoxicity and ischemia due to added epinephrine.

It is likely that more than 1 factor is at issue with many of the incidents of PAND, but the precise contribution of any single component is difficult to delineate. For example, if a needle is introduced too close to a nerve, this could result in all of the following: mechanical cutting, concentrated and prolonged contact with local anesthetic due to breach of the epineurium, and an intraneural injection with pressure injection trauma and resultant ischemia to the nerve. Without the possibility of linking histological and functional examination in the intact human, the data in this realm have come almost exclusively from animal studies and extrapolation from animal models.

\section{The role of the needle}

Mechanical cutting of the nerve by a needle would appear to be an obvious primary cause of PAND, but the exact relationship between needle tip, needle type, nerve contact, and injury remains unclear. Deficits can occur without any sensory signal that a nerve was traumatized in a responsive patient and studies of peripheral nerve blocks comparing the paresthesia technique, which would at the very least suggest pressure deformation of nerves, to localization by peripheral nerve stimulator have not demonstrated a significant difference in PAND. ${ }^{16}$ Experimental work in animals regarding the optimal needle type, that is, short or long bevel, has been summarized by Selander as indicating that long bevel (sharper) needles are associated with a greater incidence but lesser degree of severity of injury, whereas short bevel needles decrease the incidence of injuries but the injuries they produce could be more severe. ${ }^{17-19}$

\section{Intraneural injection}

Investigators have attempted to identify clinical indicators of intraneural injection and define the features that distinguish an intraneural/intrafascicular injection from the probably more benign intraneural but extrafascicular injection. A landmark study using a rabbit sciatic nerve model indicated that direct topical application of local anesthetic to nerves did not cause any histopathologic change but intrafascicular injection of either physiologic saline or bupivacaine did. ${ }^{20}$ Hadzic et al ${ }^{21}$ refined the understanding of intraneural injection by evaluating injection pressures and their relationship to nerve injury in a dog sciatic nerve model. They found that low injection pressures $(<11 \psi$ or $75.8 \mathrm{kPa}$ ) during intentional intraneural injection were associated with a return to normal motor function, whereas persistent motor deficits were observed in all nerves where high-injection pressures ( $>25 \psi$ or $172.3 \mathrm{kPa}$ ) were observed. In addition to these changes in function, subsequent histologic examination showed destruction of neural architecture and degeneration of axons in all nerves with high-pressure injections. Using the same model, other investigators reported similar findings in that all perineural injections were associated with injection pressures less than $5 \psi(34.5 \mathrm{kPa})$, whereas intraneural injections with pressures less than $12 \psi(82.7 \mathrm{kPa})$ were associated with more prolonged blocks ( 24 hours) but no persistent deficits and injections with pressures greater than $20 \psi(137.9 \mathrm{kPa})$ were associated with persistent deficits. ${ }^{22}$

A recent study by Lupu et al ${ }^{23}$ using ultrasound to visualize neural expansion with intraneural injection in a pig model were consistent with other studies of intraneural injection when some of the essential differences in study design are considered. Lupu's group did not find any persistent nerve deficits with their experimental intraneural injections, but they did not generate any injection pressures in the range that was associated with persistent deficits in other studies. Their data did not suggest any correlation between the maximum volume injected, pressure generated, or the relative increase in nerve cross-sectional area with the semiquantitative or graded presence of any histologic markers of inflammation or injury.

In another study of ultrasound visualization of intraneural injection, Bigeleisen ${ }^{24}$ documented ultrasound visualized neural expansion in 72 out of a total of 104 nerves injected in a cohort of 26 adults receiving an axillary block, with no clinical evidence of deficits at 6 months. Bigeleisen's case series is underpowered to address the safety of intraneural injection as determined by ultrasound. From this work, we can only conclude that it does not invariably result in long-term injury, 
but the practice of actively seeking to achieve nerve expansion on ultrasound-guided injection cannot be recommended.

\section{Neurotoxicity of local anesthetics}

The desired effects of sensory and motor neural signal inhibition by local anesthetics are in themselves evidence of their toxicity, which under most conditions appears to be entirely reversible. Animal studies using varied end points such as percentage of nerves demonstrating axonal degeneration, decrease in neural blood flow, inhibition of rapid axonal transport, and formation of endoneurial edema have suggested that the occurrence of these potential indicators of neurotoxicity paralleled the potency of the local anesthetic used and increased with both concentration and time duration of the application..$^{25-28}$

\section{The role of epinephrine}

Epinephrine has an established position of being one of the most frequently used additives to local anesthetics with a possible role as a marker of intravascular injection and a role in decreasing the reabsorption of local anesthetic in order to extend the duration of action and decrease the peak plasma level. The evidence for these beneficial effects must be weighed against findings from animal studies indicating that when epinephrine is used as an additive, there is a greater degree of histopathologic change with intrafascicular injection, a more significant decrease in neural blood flow, and greater inhibition of rapid axonal transport. ${ }^{20,26}$

\section{Incidence of postanesthetic nerve deficits}

Prospective studies with active surveillance by multiple assessments generally produce higher estimates of risk for PAND than do studies with more passive systems of detection of complications, for example, patient self-reporting or anesthesiologist voluntary reporting. This is most dramatically illustrated in a comparison of Borgeat et al's study of nerve deficits after interscalene block with the national prospective survey of voluntary self-reporting by French anesthesiologists by Auroy et al. ${ }^{29,30}$ Borgeat performed a prospective study with multiple interviews and follow-up with EMG studies for symptomatic patients and found that at day $10,14 \%$ of patients had paresthesia, dysesthesia, or pain apparently unrelated to surgery. At 1 month, the incidence had declined to $8 \%$ and at 9 months after surgery to $0.2 \%$. If one considers the $14 \%$ incidence of largely temporary complications from Borgeat's study, then there is an almost 500 -fold difference in incidence in comparison to Auroy's study where voluntary reports by anesthesiologists generated a $0.03 \%$ incidence for peripheral nerve blocks in the same anatomic site. Admittedly, Auroy's group was focusing on what they described as "major complications," but the degree of patient distress caused by temporary neural deficits should not be dismissed as minor in all situations.

Brull et $\mathrm{al}^{31}$ generated risk estimates for neurological complications for both central and peripheral nerve blocks by reviewing studies of regional anesthesia complications published between 1995 and 2005 and found significant heterogeneity among studies with regard to design and execution. In spite of this heterogeneity, there were substantial similarities in the patterns of injuries, that is, neurological complications were primarily sensory and almost all injuries resolved within months of the onset. Examining and combining the results of all these studies, Brull et al produced contemporary risk estimates: for all neurological injuries after spinal anesthesia, their estimate was $3.78 / 10,000$ with a range of $0-4.2 / 10,000$ for permanent injury, whereas for epidural anesthesia, the estimates were 2.19/10,000 for all injuries and a range of 0-7.6/10,000 for permanent injury. The incidence rates of neural deficits with peripheral nerve blocks were significantly higher, but the risk of permanent injury was less as there was only 1 report of a peripheral nerve block associated permanent injury in all the studies included in the review. Interscalene brachial plexus block was associated with a risk of temporary injury of 2.84/100, axillary brachial plexus block with an estimate of $1.48 / 100$, and the risk for femoral nerve block was $0.34 / 100$. Case reports of permanent sensory and motor injuries after peripheral nerve block are uncommon, but are worrisome to any practitioner of regional anesthesia as they appear to defy any systematic examination for common causal factors and preventive strategies. ${ }^{32,33}$

\section{Hemorrhagic complications causing neural deficits}

The anatomic features of the neuraxis that make regional anesthetic blocks so effective in this area make the complications associated with them potentially more devastating. One of the most feared is vertebral canal hematoma. Hemorrhagic complications can also occur with peripheral nerve blocks, but rarely does this result in longer term neurologic consequences. The incidence of vertebral canal hematoma associated with prolonged neurologic injury has been estimated as being as uncommon as $1: 1,000,000,{ }^{34}$ other studies have, however, reported a much higher incidence (Table 1$).{ }^{35}$

Studies with sufficiently large numbers to define subgroups suggest that the risk of hematoma is substantially different for select patient populations. Moen et $\mathrm{al}^{41}$ reported an incidence of epidural hematoma in women receiving epidural labor analgesia of $1 / 200,000$, whereas it was estimated to be as 
Table I Hematoma associated with neuraxial anesthesia

\begin{tabular}{|c|c|c|c|c|}
\hline Author & Country/region & Type of neuraxial block & Time period of study & $\begin{array}{l}\text { Incidence of vertebral } \\
\text { canal hematoma }\end{array}$ \\
\hline $\begin{array}{l}\text { Dahlgren } \\
\text { and Tornebrandt }{ }^{35}\end{array}$ & Sweden & Epidural & $|99|-1994$ & $\begin{array}{l}3 / 9,232(0.03 \%) \text { all resulting } \\
\text { in paraplegia }\end{array}$ \\
\hline Cameron et al ${ }^{36}$ & Australia & Epidural & $1990-2005$ & $\begin{array}{l}2 / 8,210(0.024 \%) \text { no persistent } \\
\text { deficits }\end{array}$ \\
\hline Christie et $\mathrm{a}^{37}$ & New Zealand & Epidural & 2000-2005 & $\begin{array}{l}3 / 8,100(0.037 \%) \text { I complete } \\
\text { recovery, } 2 \text { persistent deficits }\end{array}$ \\
\hline Cook et al ${ }^{38}$ & United Kingdom & Epidural & 2006-2008 & $\begin{array}{l}6 / 707,000(0.00085 \%) 3 \text { partial } \\
\text { neurologic recovery, I complete } \\
\text { recovery }\end{array}$ \\
\hline $\begin{array}{l}\text { Pöpping et } \mathrm{al}^{39} \\
\text { Scott et } \mathrm{al}^{40}\end{array}$ & $\begin{array}{l}\text { Germany } \\
\text { Australia }\end{array}$ & $\begin{array}{l}\text { Epidural } \\
\text { Epidural }\end{array}$ & $\begin{array}{l}1998-2006 \\
1990-1993\end{array}$ & $\begin{array}{l}I / 4,74 \mid(0.02 \%) \\
2 / I, 0 \mid 4(0.2 \%)\end{array}$ \\
\hline Moen et al ${ }^{41}$ & Sweden & $\begin{array}{l}\text { Epidural/CSE } \\
\text { SAB/continuous SAB }\end{array}$ & $1990-1999$ & $\begin{array}{l}\text { I/I0,300 }(0.0097 \%) \text { for epidural } \\
\text { and CSE combined I/480,000 } \\
(0.0002 \%) \text { for SAB }\end{array}$ \\
\hline
\end{tabular}

Abbreviations: CSE, combined spinal-epidural; SAB, subarachnoid block.

high as 1/3,600 in women receiving epidurals for total knee arthroplasty. However, even in this relatively large study, the number of cases available for risk calculation in the smaller subgroups results in wide confidence intervals leaving open the possibility that this high incidence may be the result of case clustering. Analysis of individual case reports of hematoma have suggested that the use of anticoagulation therapy around the time of the block placement or catheter removal, advanced age of the patient, female gender, and reduced renal function are features combining to create a potentially higher risk profile for this complication. ${ }^{42}$

Only $38 \%$ of patients with symptomatic vertebral canal hematomas will present with radicular pain, so the new onset of motor block may be the first and most reliable sign ${ }^{43}$ Regular neurologic examinations and the use of analgesic solutions with dilute local anesthetic concentrations to minimize the occurrence of dense motor block during continuous epidural analgesia may enhance the early detection and diagnosis of vertebral canal hematomas accompanying regional analgesia. Data suggest that the time from onset of symptomatic vertebral canal hematomas to the time of surgical intervention is crucial to improving outcomes, with some investigators expressing the opinion that the goal should be to keep that interval to less than 8 hours. ${ }^{42}$

Peripheral nerve blocks have not been associated with significant hemorrhagic complications leading to neurologic adverse events as frequently as neuraxial blocks; however, when the American Society of Regional Anesthesia updated its guidelines regarding regional anesthesia and anticoagulation in 2009, the authors indicated that the guidelines for neuraxial blocks and anticoagulation should now also be applied to peripheral nerve blocks. ${ }^{42}$ The level of evidence supporting this extension of the recommendations was graded as $1 \mathrm{C}$, indicating that the published evidence was weak, but the authors were unanimous in their agreement on the guideline. They also noted that there was a paucity of information on which to establish the recommendation as there were only 26 cases of peripheral nerve block with hemorrhagic complications in the literature. These complications have been reported in patients with normal coagulation profiles, but the most severe, including death due to hemorrhage, occurred with deep blocks such as lumbar sympathetic blocks in anticoagulated patients. ${ }^{44}$

\section{Infection causing neurological adverse events}

Similar to hemorrhagic complications, infection is another complication that is most devastating when it occurs in the setting of neuraxial anesthesia and has widely variable estimates of incidence of many of its manifestations. Meningitis after spinal anesthesia has been estimated to be as infrequent as 1 in $21,000-53,000^{45}$ in a 1994 study and at 1/235,000 in a more recent study ${ }^{38}$ This makes the occurrence of 2 recently reported clusters of meningitis after intrapartum spinal analgesia all the more notable. ${ }^{46}$ These clusters, 1 of 3 cases and a second of 2 cases, were linked to bacteria cultured from the oral flora of the 2 anesthesiologists who did not wear masks during the procedures, reinforcing the importance of following asepsis guidelines for regional anesthesia procedures. A 2006 review by Hebl comprehensively examined the importance of asepsis in the practice of regional anesthesia, including the potential advantages of the use of chlorhexidine for skin preparation..$^{47-49}$

The more common infectious complication associated with neuraxial anesthesia and analgesia is that of deep space infection associated with epidural catheters. Table 2 summarizes incidence results from representative studies of this complication. Although signs and symptoms such as severe back pain, local back tenderness, and fever have been 
Table 2 Deep space infections associated epidural catheters

\begin{tabular}{llll}
\hline Author & Country & $\begin{array}{l}\text { Study time } \\
\text { frame }\end{array}$ & Incidence \\
\hline Green and & Australia & $2002-2005$ & $\begin{array}{l}0.04 \% \text { deep space infection } \\
0.02 \% \text { paraspinous and }\end{array}$ \\
Paech $^{53}$ & & & $\begin{array}{l}\text { epidural abscess } \\
\end{array}$ \\
${\text { Cameron et } \mathrm{al}^{36}}$ & Australia & - & $0.07 \%$ epidural abscess \\
${\text { Popping et } \mathrm{al}^{39}}$ & Germany & $1998-2006$ & $0.014 \%$ epidural abscess \\
Wang et al $^{54}$ & Denmark & $1997-1998$ & $0.05 \%$ epidural abscess \\
\hline
\end{tabular}

associated in some series with epidural abscess, ${ }^{50}$ other case reports and series emphasize the potential for both atypical and delayed presentations of this problem, suggesting that a high index of suspicion has to be maintained when assessing signs and symptoms occurring after the use of neuraxial anesthesia or analgesia. ${ }^{51,52}$

In a manner analogous to single shot and continuous neuraxial blocks, single shot peripheral nerve blocks appear to be at less of a risk for infection than continuous peripheral blocks and when they do happen, less of a risk for persistent nerve deficits. A case report of fatal necrotizing fasciitis after a single shot axillary block, however, emphasizes that even in this lower risk setting there is a need for constant vigilance toward maintaining aseptic technique, as this complication occurred in the setting of the provider not wearing a mask. ${ }^{55}$ There is variability in the reported frequency of infection with continuous peripheral nerve block with localized infection occurring between $0 \%$ and $3 \%$ of the time, whereas proven systemic infection related to the catheter site occurred with $0 \%-0.9 \%$ of blocks. ${ }^{56}$ Many episodes are associated with no more than redness at the catheter site with treatment consisting of catheter removal, occasionally antibiotic therapy, and rarely surgical drainage. There have, however, been at least 2 case reports of severe life-threatening infections with continuous peripheral nerve blocks, both were at the interscalene site and both had a delay in onset of signs and symptoms until after the catheter had been removed. ${ }^{57,58}$ These infections required surgical drainage, prolonged antibiotic treatment, and prolonged intensive care unit stays.

\section{Intravascular injection of local anesthetic and local anesthetic toxicity}

Unrecognized intravascular injection of local anesthetic with resultant toxicity is a dramatic complication when it results in neurologic toxicity with seizures and potentially fatal when the intravascular dose reaches the cardiovascular toxicity threshold. The reports primarily refer to neurologic toxicity, that is seizures and alterations in consciousness, as cardiovascular collapse and death are exceedingly rare. The reported rate of occurrence varies with the anatomical location of the block in part due to the relative vascularity of the nerve or plexus being blocked, but has also varied considerably with the type of study reporting this complication. Auroy et $\mathrm{al}^{29}$ reported an incidence of seizures in upper extremity blocks of 3 in $23,784(0.013 \%) .{ }^{29}$ At the upper range of incidence for larger studies reporting on upper extremity blocks, is Orebaugh et al's ${ }^{59}$ retrospective series gathered for a quality improvement study done in part to assess the introduction and use of ultrasound guidance in their practice. In this study, brachial plexus blocks performed with a peripheral nerve stimulator were associated with an incidence of LAST of 4 in 988 (0.4\%), 30 times higher than that of Auroy's study, whereas none of the 1,313 blocks performed with ultrasound guidance were associated with this complication. This was a statistically significant difference making this one of the only publications with outcome data supporting the conjecture that there is a safety advantage for ultrasound guidance. ${ }^{60}$ These data are weakened, however, by their use of historic controls. Other case reports of unrecognized intravascular injection during the performance of peripheral nerve blocks with ultrasound guidance ${ }^{61}$ emphasize that the use of ultrasound cannot supplant the practice of intermittent aspiration and injection of volumes of local anesthetic slowly enough for each individual injection to act as a test dose. Intermediate between the incidence estimates generated by these studies above is Brown's et al's large single center retrospective study reporting a seizure incidence of $0.2 \% .^{62}$ Findings in smaller studies by Weber and Jain $0.5 \%{ }^{63}$ and Borgeat $0.2 \%{ }^{30}$ are in accord with all the other estimates except that of Auroy, raising the question of either a significant difference in technique between the settings for these studies or of the possibility of under-reporting.

\section{Transient neurologic symptoms after spinal anesthesia}

Mild to severe pain originating in the gluteal region, usually appearing within the first 24 hours after recovery from a spinal anesthetic and radiating to both lower extremities, has been called transient neurologic symptoms (TNS). ${ }^{64,65}$ This clinical constellation had previously been called both transient radicular irritation and transient neurologic toxicity. TNS has been defined only by clinical symptoms as there have been no associated abnormalities on magnetic resonance imaging, electropathological testing, or clinical examination. ${ }^{66}$ TNS has been associated with the use of 
lidocaine for spinal anesthesia, lithotomy position, and degree of activity postoperatively. The recognition of TNS has led many practitioners to abandon the use of lidocaine for spinal anesthesia, with the strongest association having been with $5 \%$ hyperbaric lidocaine and spinal microcatheters. ${ }^{67}$

\section{Miscellaneous neurological adverse events}

Any anatomic structure in close proximity to nerve block sites is potentially vulnerable to trauma from misdirection of the block needle, and other "bystander" nerves are susceptible to both needle trauma and unintentional block with local anesthetic. The interscalene and supraclavicular blocks have perhaps the greatest potential for the occurrence of these problems due to the proximity of the block sites to critical anatomical structures in the neck. Interscalene blocks have been associated with ipsilateral phrenic nerve block with an incidence as high as $100 \%$ and this has occurred in up to $67 \%$ supraclavicular blocks. ${ }^{68,69}$ It is more useful to consider the transient hemi-diaphragmatic dysfunction that occurs due to phrenic nerve block to be a complication only when it results in respiratory distress, which is far less common. Investigators have assessed the use of ultrasound guidance and reductions in local anesthetic volume on the incidence of phrenic nerve block and have found that they were able to provide clinically effective analgesia with 5 and $10 \mathrm{~mL}$ of local anesthetic with an incidence of phrenic nerve block of $13 \%$ in 1 study and $45 \%$ in another. ${ }^{70,71}$

The nerves of the cervical plexus are obviously vulnerable to injury with cervical plexus blocks, but they are also subjected to bystander injury with brachial plexus blocks above the clavicle. Christ et $\mathrm{al}^{72}$ evaluated patients who received an interscalene block with the modified lateral approach and found that $8 \%$ of patients showed symptoms consistent with superficial cervical plexus neuropathy at 24 hours. The symptoms consisted of hypesthesia in 1-4 cutaneous branches of the cervical plexus. Symptoms lasted for more than 1 month in $2 \%$ of patients, but had all resolved after 6 months.

Misdirected needles near the spinal cord have resulted in total spinal anesthesia and in catastrophic incidents of spinal cord damage with interscalene, lumbar plexus, and celiac plexus blocks. ${ }^{73-75}$ A published case series of total spinal anesthesia and injections into the spinal cord with interscalene blocks done with the patients under general anesthesia initiated an ongoing discussion with regard to the safety and appropriateness of performing any peripheral nerve blocks in adults under general anesthesia. ${ }^{76,77}$

\section{The impact of ultrasound guidance on neurological adverse outcomes}

Due to their uncommon nature, a sufficiently powered, randomized trial examining the incidence of PAND with ultrasound guidance in comparison to other localizing techniques has not been completed nor is it likely to be forthcoming. ${ }^{60,78}$ Liu et $\mathrm{al}^{79}$ examined the incidence of postoperative neurological symptoms after interscalene blocks performed with ultrasound or peripheral nerve stimulator and did not detect any difference, but with 219 patients completing the study it appears to have been underpowered for studying PAND. Orebaugh et al's $\mathrm{s}^{59}$ aforementioned retrospective review suggested that the risk of intravascular injection could be reduced with the use of ultrasound but an audit by Barrington et a ${ }^{61}$ reported no difference in the incidence of LAST when it has been used, in spite of its use having been associated with a statistically significant fewer number of vascular punctures. In contrast to the supposition of increased safety with ultrasound, 1 expert hypothesized that the use of ultrasound is not only unproven to enhance safety, but also that the ultrasound transducer has potential to increase the risk of contamination and infection. ${ }^{78}$ There are, however no case reports or other evidence supporting this assertion. Comparison of rates of neurological adverse events in studies using ultrasound to other techniques must be considered in light of the validity of using historic controls and the difficulty of generating sufficient statistical power even when using data from relatively large audits. At this point, there does not appear to be evidence to support or refute the suggestion of a significant reduction in neurological adverse outcomes associated with the use of ultrasound guidance in regional anesthesia.

\section{Conclusions}

The uncommon nature of severe neurological adverse events associated with regional anesthesia is to some extent reassuring to its practitioners and their patients who benefit from its application, but this does not diminish their significance nor does it obviate the need to strive for even greater safety. Further decreases in the frequency of neurological complications may come with incremental advances of our knowledge and the application of new technology but it is unlikely that there will be any silver bullets that will eliminate the problem completely, including ultrasound guidance. Incidence estimates for many of the neurological adverse events vary widely due to the challenges associated with the study of rare events. Further refinements and expansion of our admittedly incomplete knowledge of the prevention of neurological adverse events will help us 
balance the many benefits of regional anesthesia against its infrequent but important complications.

\section{Disclosure}

The authors report no conflicts of interest in this work.

\section{References}

1. Stojadinovic A, Shockey SM, Croll SM, Buckenmaier CC, 3rd. Quality of reporting of regional anesthesia outcomes in the literature. Pain Med. 2009;10(6):1123-1131.

2. Cullen DJ, Bates DW, Small SD, Nemeskal AR, Leape LL. The incident reporting system does not detect adverse drug events: a problem for quality improvement. Jt Comm J Qual Improv. 1995;21(10): 541-548.

3. Horlocker TT. What's a nice patient like you doing with a complication like this? Diagn progn prev spinal hematoma. 2004;51(6):527-534.

4. Tryba M. Epidural regional anesthesia and low molecular heparine: pro (German). Anasthesiol Intensivmed Notfallmed Schmerzther. 1993;28:179-181.

5. Hanley JA, Lippman-Hand A. If nothing goes wrong, is everything alright? JAMA. 1983;259:1743-1745.

6. Richman JM, Liu SS, Courpas G, et al. Does continuous peripheral nerve block provide superior pain control to opioids? A Meta-Analysis. Anesth Analg. 2006;102(1):248-257.

7. Hadzic A, Arliss J, Kerimoglu B, et al. A comparison of infraclavicular nerve block versus general anesthesia for hand and wrist day-case surgeries. Anesthesiology. 2004;101(1):127-132.

8. Liu S, Strodtbeck WM, Richman JM, Wu CL. A comparison of regional versus general anesthesia for ambulatory anesthesia: a metaanalysis of randomized controlled trials. Anesth Analg. 2005;101(6): 1634-1642.

9. Hadzic A, Williams BA, Karaca PE, et al. For outpatient rotator cuff surgery, nerve block anesthesia provides superior same-day recovery over general anesthesia. Anesthesiology. 2005;102(5):1001-1007.

10. Momeni M, Crucitti M, de Kock M. Patient-controlled analgesia in the management of postoperative pain. Drugs. 2006;66(18):2321-2337.

11. Hawkins JL, Koonin LM, Palmer SK, Gibbs CP. Anesthesia-related deaths during obstetric delivery in the United States, 1979-1990. Anesthesiology. 1997;86(2):277-284.

12. Department of Health and others. Why Mothers Die 1997-1999. The Confidential Enquiries into Maternal Deaths in the United Kingdom. London: RCOG Press; 2001.

13. Rodgers A, Walker N, Schug S, et al. Reduction of postoperative mortality and morbidity with epidural or spinal anaesthesia: results from overview of randomised trials. BMJ. 2000;321(7275):1493.

14. Park WY, Thompson JS, Lee KK. Effect of epidural anesthesia and analgesia on perioperative outcome: a randomized, controlled Veterans Affairs cooperative study. Ann Surg. 2001;234(4):560-569.

15. Yeager MP, Carli F. Anesthesia and surgical outcomes: an orphean ambition [editorial]. Reg Anesth Pain Med. 2004;29(6):515.

16. Selander D, Edshage S, Wolff T. Paresthesiae or no paresthesiae? Nerve lesions after axillary blocks. Acta Anaesthesiol Scand. 1979;23(1): 27-33.

17. Selander D, Dhunér KG, Lundborg G. Peripheral nerve injury due to injection needles used for regional anesthesia. An experimental study of the acute effects of needle point trauma. Acta Anaesthesiol Scand. 1977;21(3):182-188.

18. Rice AS, McMahon SB. Peripheral nerve injury caused by injection needles used in regional anaesthesia: influence of bevel configuration, studied in a rat model. Br J Anaesth. 1992;69(5):433-438.

19. Selander DE. Labat lecture 2006. Regional anesthesia: aspects, thoughts, and some honest ethics; about needle bevels and nerve lesions, and back pain after spinal anesthesia. Reg Anesth Pain Med. 2007;32(4): 341-350.
20. Selander D, Brattsand R, Lundborg G, Nordborg C, Olsson Y. Local anesthetics: importance of mode of application, concentration and adrenaline for the appearance of nerve lesions. An experimental study of axonal degeneration and barrier damage after intrafascicular injection or topical application of bupivacaine (Marcain). Acta Anaesthesiol Scand. 1979;23(2):127-136.

21. Hadzic A, Dilberovic F, Shah S, et al. Combination of intraneural injection and high injection pressure leads to fascicular injury and neurologic deficits in dogs. Reg Anesth Pain Med. 2004;29(5):417-423.

22. Kapur E, Vuckovic I, Dilberovic F, et al. Neurologic and histologic outcome after intraneural injections of lidocaine in canine sciatic nerves. Acta Anaesthesiol Scand. 2007;51(1):101-107.

23. Lupu CM, Kiehl T, Chan VWS, El-Beheiry H, Madden M, Brull R. Nerve expansion seen on ultrasound predicts histologic but not functional nerve injury after intraneural injection in pigs. Reg Anesth Pain Med. 2010;35(2):132-139.

24. Bigeleisen PE. Nerve puncture and apparent intraneural injection during ultrasound-guided axillary block does not invariably result in neurologic injury. Anesthesiology. 2006;105(4):779-783.

25. Kalichman MW, Powell HC, Myers RR. Quantitative histologic analysis of local anesthetic-induced injury to rat sciatic nerve. J Pharmacol Exp Ther. 1989;250(1):406-413.

26. Myers RR, Heckman HM. Effects of local anesthesia on nerve blood flow: studies using lidocaine with and without epinephrine. Anesthesiology. 1989;71(5):757-762.

27. Fink BR, Kish SJ. Reversible inhibition of rapid axonal transport in vivo by lidocaine hydrochloride. Anesthesiology. 1976;44(2):139-146.

28. Kroin JS, Penn RD, Levy FE, Kerns JM. Effect of repetitive lidocaine infusion on peripheral nerve. Exp Neurol. 1986;94(1):166-173.

29. Auroy Y, Benhamou D, Bargues L, et al. Major complications of regional anesthesia in France: The SOS Regional Anesthesia Hotline Service. Anesthesiology. 2002;97(5):1274-1280.

30. Borgeat A, Ekatodramis G, Kalberer F, Benz C. Acute and non acute complications associated with interscalene block and shoulder surgery. Anesthesiology. 2001;95(4):875-880.

31. Brull R, McCartney CJ, Chan VW, El-Beheiry H. Neurological complications after regional anesthesia: contemporary estimates of risk. Anesth Analg. 2007;104(4):965-974.

32. Borgeat A, Aguirre J, Curt A. Case scenario: neurologic complication after continuous interscalene block. Anesthesiology. 2010;112(3):742-745.

33. Koff MD, Cohen JA, McIntyre JJ, Carr CF, Sites BD. Severe brachial plexopathy after an ultrasound-guided single-injection nerve block for total shoulder arthroplasty in a patient with multiple sclerosis. Anesthesiology. 2008;108(2):325-328.

34. Tryba M, Wedel DJ. Central neuraxial block and low molecular weight heparin (enoxaparin): lessons learned from different dosage regimens in two continents. Acta Anaesthesiol Scand. 1997;41 Suppl III: $100-104$.

35. Dahlgren N, Tornebrandt K. Neurological complications after anaesthesia. A follow-up of 18,000 spinal and epidural anaesthetics performed over three years. Acta Anaesthesiol Scand. 1995;39(7):872-880.

36. Cameron CM, Scott DA, McDonald WM, Davies MJ. A review of neuraxial epidural morbidity: experience of more than 8,000 cases at a single teaching hospital. Anesthesiology. 2007;106(5):997-1002.

37. Christie IW, McCabe S. Major complications of epidural analgesia after surgery: results of a six-year survey. Anaesthesia. 2007;62(4):335-341.

38. Cook TM, Counsell D, Wildsmith JA. Major complications of central neuraxial block: report on the Third National Audit Project of the Royal College of Anaesthetists. Br J Anaesth. 2009;102(2):179-190.

39. Pöpping DM, Zahn PK, van Aken HK, Dasch B, Boche R, Pogatzki-Zahn EM. Effectiveness and safety of postoperative pain management: a survey of 18925 consecutive patients between 1998 and 2006 (2nd revision): a database analysis of prospectively raised data. Br J Anaesth. 2008;101(6):832-840.

40. Scott DA, Beilby DSN, Mcclymont C. Postoperative analgesia using epidural infusions of fentanyl with bupivacaine - a prospective analysis of 1,014 patients. Anesthesiology. 1995;83(4):727-737. 
41. Moen V, Dahlgren N, Irestedt L. Severe neurological complications after central neuraxial blockades in Sweden 1990-1999. Anesthesiology. 2004;101(4):950-959.

42. Horlocker TT, Wedel DJ, Rowlingson JC, et al. Regional anesthesia in the patient receiving antithrombotic or thrombolytic therapy: American Society of Regional Anesthesia and Pain Medicine Evidence-Based Guidelines (Third Edition). Reg Anesth Pain Med. 2009;35: 64-101.

43. Vandermeulen EP, van Aken H, Vermelyn J. Anticoagulants and spinal-epidural analgesia. Anesth Analg. 1994;79(6):1165-1177.

44. Maier C, Gleim M, Weiss T, Stachetzki U, Nicolas V, Zenz M. Severe bleeding following lumbar sympathetic blockade in two patients under medication with irreversible platelet aggregation inhibitors. Anesthesiology. 2002;97(3):740-743.

45. Kane RE. Neurologic deficits following epidural or spinal anesthesia Anesth Analg. 1981;60(3):150-161.

46. Bacterial meningitis after intrapartum spinal anesthesia - New York and Ohio, 2008-2009. MMWR Morb Mortal Wkly Rep. 2010;59:65-69.

47. Hebl JR. The importance and implications of aseptic techniques during regional anesthesia. Reg Anesth Pain Med. 2006;31(4):311-323.

48. Kinirons B, Mimoz O, Lafendi L, Naas T, Meunier J, Nordmann P. Chlorhexidine versus povidone iodine in preventing colonization of continuous epidural catheters in children: a randomized, controlled trial. Anesthesiology. 2001;94:239-244.

49. Sato S, Sakuragi T, Dan K. Human skin flora as a potential source of epidural abscess. Anesthesiology. 1996;85:1276-1282.

50. Martin RJ, Yuan HA. Neurosurgical care of spinal epidural, subdural, and intramedullary ancesses and arachnoiditis. Orthop Clin North Am. 1996;27(1):125-136.

51. Reihsaus E, Waldbaur H, Seeling W. Spinal epidural abscess. A metaanalysis of 915 patients. Neurosurg Rev. 2000;23(4):175-204.

52. Hernandez JM, Coyle FP, Wright CD, Ballantyne JC. Epidural abscess after epidural anesthesia and continuous epidural analgesia in a patient with gastric lymphoma. J Clin Anesth. 2003;15(1):48-51.

53. Green LK, Paech MJ. Obstetric epidural catheter-related infections at a major teaching hospital: a retrospective case series. Int JObstet Anesth. 2010;19(1):38-43.

54. Wang LP, Hauerberg J, Schmidt JF. Incidence of spinal epidural abscess after epidural analgesia. Anesthesiology. 1999;91(6):1928-1936.

55. Nseir S, Pronnier P, Soubrier S, et al. Fatal streptococcal necrotizing fasciitis as a complication of axillary brachial plexus block. $\mathrm{Br} J$ Anaesth. 2004;92(3):427-429.

56. Capdevila X, Bringuier S, Borgeat A. Infectious risk of continuous peripheral nerve blocks. Anesthesiology. 2009;110(1):182-188.

57. Capdevila X, Jaber S, Pesonen P, Borgeat A, Eledjam JJ. Acute neck cellulitis and mediastinitis complicating a continuous interscalene block. Anesth Analg. 2008;107(4):1419-1421.

58. Clenenden SR, Robards CB, Wang RD, Greengrass RA. Continuous interscalene block associated with neck hematoma and postoperative sepsis. Anesth Analg. 2010;110(4):1236-1238.

59. Orebaugh SL, Williams BA, Vallejo M, Kentor ML. Adverse outcomes associated with stimulator-based peripheral nerve blocks with versus without ultrasound visualization. Reg Anesth Pain Med. 2009;34(3):251-255.

60. Neal JM. Ultrasound-guided regional anesthesia and patient safety: an evidence-based analysis. Reg Anesth Pain Med. 2010;35 Suppl 2: S59-S67.

Local and Regional Anesthesia

\section{Publish your work in this journal}

Local and Regional Anesthesia is an international, peer-reviewed, open access journal publishing on the development, pharmacology, delivery and targeting and clinical use of local and regional anesthetics and analgesics. The journal welcomes submitted papers covering original research, basic science, clinical studies, reviews \& evaluations,
61. Barrington MJ, Watts SA, Gledhill SR, et al. Preliminary results of the Australasian regional anaesthesia collaboration: A prospective audit of more than 7000 peripheral nerve and plexus blocks for neurologic and other complications. Reg Anesth Pain Med. 2009;34(6):534-541.

62. Brown DL, Ransom DM, Hall JA, Leicht CH, Schroeder DR, Offord KP. Regional anesthesia and local anesthetic-induced systemic toxicity: seizure frequency and accompanying cardiovascular changes. Anesth Analg. 1995;81(2):321-328.

63. Weber SC, Jain R. Scalene regional anesthesia for shoulder surgery in a community setting: an assessment of risk. J Bone Joint Surg Am 2002;84-A(5):775-779.

64. Hampl KF, Schneider MC, Ummenhofer W, Drewe J. Transient neurological symptoms after spinal anesthesia. Anesth Analg. 1995;81(6):1148-1153.

65. Pollock JE, Neal JM, Stephensen CA, Wiley CE. Prospective study of the incidence of transient radicular irritation in patients undergoing spinal anesthesia. Anesthesiology. 1996(6);84:1361-1367.

66. Pollock JE, Burkhead D, Neal JM, et al. Spinal nerve function in five volunteers experiencing transient neurologic symptoms after lidocaine subarachnoid anesthesia. Anesth Analg. 2000;90(3):658-665.

67. Drasner K. Lidocaine spinal anesthesia: a vanishing therapeutic index? Anesthesiology. 1997;87(3):469-472.

68. Urmey WF, Talts KH, Sharrock NE. One hundred percent incidence of hemidiaphragmatic paresis associated with interscalene brachial plexus anesthesia as diagnosed by ultrasonography. Anesth Analg. 1991;72(4):498-503.

69. Knoblanche GE. The incidence and aetiology of phrenic nerve blockade associated with supraclavicular brachial plexus block. Anaesth Intensive Care. 1979;7(4):346-349.

70. Riazi S, Carmichael N, Awad I, Holtby RM, McCartney CJ. Effect of local anaesthetic volume ( $20 \mathrm{vs} 5 \mathrm{~mL}$ ) on the efficacy and respiratory consequences of ultrasound-guided interscalene brachial plexus block. Br J Anaesth. 2008;101(4):549-556.

71. Renes SH, Rettig HC, Gielen MJ, Wilder-Smith OH, Geffen van GJ. Ultrasound guided low-dose interscalene brachial plexus block reduces the incidence of hemidiaphragmatic paresis. Reg Anesth Pain Med. 2009;34(6):498-502.

72. Christ S, Rindfleisch F, Friederich P. Superficial cervical plexus neuropathy after single-injection interscalene brachial plexus block. Anesth Analg. 2009;109(6):2008-2011.

73. Ross S, Scarborough CD. Total spinal anesthesia following brachialplexus block. Anesthesiology. 1973;39(4):458.

74. Gentili M, Aveline C, Bonnet F. Total spinal anesthesia complicating posterior lumbar plexus block. Ann Fr Anesth Reanim. 1998;17(7):740-742.

75. Cherry DA, Lamberty J. Paraplegia following coeliac plexus block. Anaesth Intensive Care. 1984;12(1):59-61.

76. Benumof JL. Permanent loss of cervical spinal cord function associated with interscalene block performed under general anesthesia. Anesthesiology. 2000(6);93:1541-1545.

77. Bernards CM, Hadzic A, Suresh S, Neal JM. Regional anesthesia in anesthetized or heavily sedated patients. Reg Anesth Pain Med. 2008;33(5):449-460.

78. Borgeat A, Capdevila X. Neurostimulation/ultrasonography: the Trojan war will not take place. Anesthesiology. 2007;106(5):896-898.

79. Liu SS, Zayas VM, Gordon MA, et al. A prospective, randomized, controlled trial comparing ultrasound versus nerve stimulator guidance for interscalene block for ambulatory shoulder surgery for postoperative neurological symptoms. Anesth Analg. 2009;109(1):265-271.

\section{Dovepress}

guidelines, expert opinion and commentary, case reports and extended reports. The manuscript management system is completely online and includes a very quick and fair peer-review system, which is all easy to use. Visit http://www.dovepress.com/testimonials.php to read real quotes from published authors. 